\title{
Hypopharyngeal injury caused by overtube insertion during endoscopic submucosal dissection
}

A 46-year-old man with a gastric lesion was referred to our hospital. Esophagogastroduodenoscopy identified a flat lesion approximately $15 \mathrm{~mm}$ in diameter in the gastric body. Biopsies were taken but a final diagnosis could not be reached because of the small size of the specimens. Endoscopic submucosal dissection (ESD) was performed to remove and retrieve the whole lesion and obtain a precise diagnosis. To enable the scope to be inserted and retrieved repeatedly, an overtube was advanced after the endoscope had been inserted into the stomach. During the procedure, the operator felt a strong resistance and immediately aborted the overtube placement.

When the patient's oral cavity was inspected, a whitish fishbone-like structure was revealed ( Fig. 1), which was diagnosed by an otolaryngologist as a fracture of the thyroid cartilage. The patient was hospitalized and medically managed with antibiotic therapy. After 9 days, the fractured thyroid cartilage was covered with an inflamed mucosa ( Fig.2). A further 5 days later, the area was covered with a whitish scar ( Fig.3) and the ESD was conducted safely and successfully. The patient's clinical course was uneventful and no further surgical intervention or medical treatment was needed to repair the hypopharyngeal injury.

There have been some reports describing the relationship between esophageal perforation and overtube placement. It remains controversial whether this type of esophageal perforation should be treated surgically or conservatively $[1,2]$. In our case, there was no mediastinitis and the patient was managed nonsurgically but required hospitalization for several days. This case highlights the need to use abundant jelly to lubricate the overtube, which should be inserted gently into the esophagus. Moreover, the angle formed by the pharynx and the esophagus should be straightened as much as possible at the time of insertion.

Endoscopy_UCTN_Code_CPL_1AH_2AJ

Competing interests: None

\section{N. Muguruma, S. Okamura, Y. Imoto, K. Okamoto, T. Sueuchi, S. Kitamura, T. Kimura, T. Takayama}

Department of Gastroenterology and Oncology, The University of Tokushima Graduate School, Tokushima, Japan

\section{References}

1 Dinning JP, Jaffe PE. Delayed presentation of esophageal perforation as a result of overtube placement. J Clin Gastroenterol 1997; 24: $250-252$

2 Holderman WH, Etzkorn KP, Patel SA et al. Endoscopic findings and overtube-related complications associated with esophageal variceal ligation. J Clin Gastroenterol 1995; 21: $91-94$

\section{Bibliography}

DOI http://dx.doi.org/

10.1055/s-0032-1309351

Endoscopy 2012; 44: E225

(c) Georg Thieme Verlag KC

Stuttgart - New York

ISSN 0013-726X

\section{Corresponding author}

\section{N. Muguruma, MD, PhD}

Department of Gastroenterology and Oncology Institute of Health Biosciences

The University of Tokushima Graduate School 3-18-15, Kuramoto-cho

Tokushima City 770-8503

Japan

Fax: +81-88-6339235

muguruma.clin.med@gmail.com

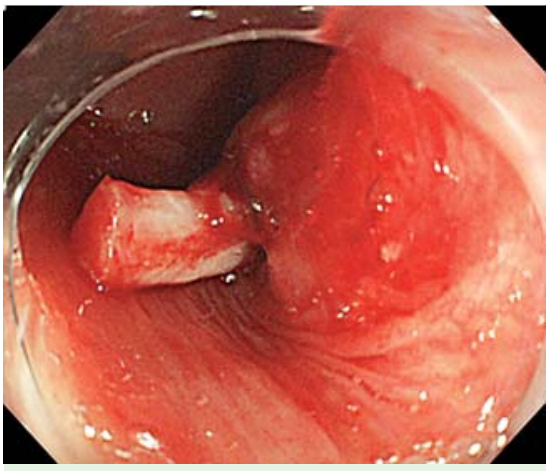

Fig. 1 A whitish fishbone-like structure is seen in the mouth of a patient who had been undergoing placement of an overtube for planned endoscopic submucosal dissection (ESD) of a gastric lesion. This was diagnosed by an otolaryngologist as a fracture of the thyroid cartilage.

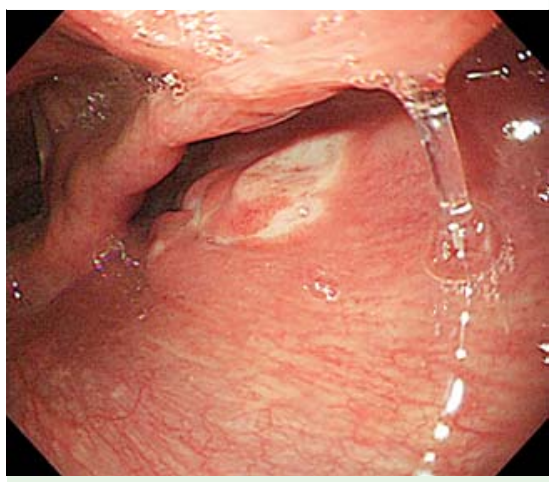

Fig. 2 Appearance of the injured area after 9 days of antibiotic therapy showing an inflamed mucosa covering the fractured thyroid cartilage.

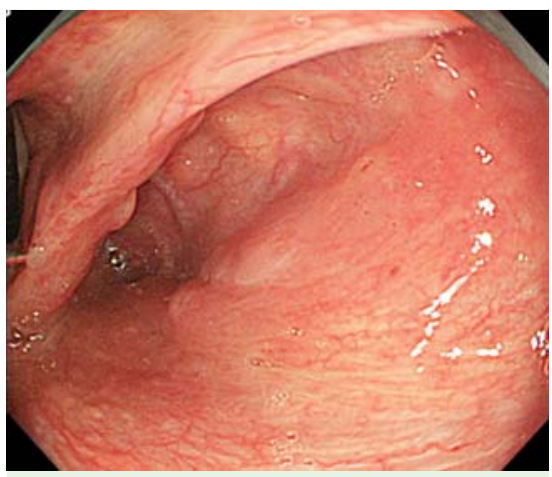

Fig. 3 Appearance of the injured area after 2 weeks showing only a whitish scar. 